\title{
Home Numeracy and Preschool Children's Mathematical Development: Expanding Home Numeracy Models to Include Parental Attitudes and Emotions
}

\author{
Ann Dowker* \\ Department of Experimental Psychology, University of Oxford, Oxford, United Kingdom
}

Most studies suggest that home numeracy is correlated with preschool children's current mathematical performance, and also predicts their mathematical performance longitudinally. However, this finding is not universal, and some studies do not suggest

OPEN ACCESS

Edited by: Amy R Napoli,

University of Nebraska-Lincoln,

United States

Reviewed by:

Monika Szczygiet,

Pedagogical University of Kraków,

Poland

Sarah Eason,

Purdue University, United States Lydia DeFlorio,

University of Nevada, Reno, United States

*Correspondence: Ann Dowker

ann.dowker@psy.ox.ac.uk

Specialty section:

This article was submitted to Educational Psychology, a section of the journal

Frontiers in Education

Received: 24 June 2020 Accepted: 04 January 2021 Published: 18 February 2021

Citation:

Dowker A (2021) Home Numeracy and

Preschool Children's Mathematical

Development: Expanding Home Numeracy Models to Include Parental

Attitudes and Emotions.

Front. Educ. 6:575664.

doi: 10.3389/feduc.2021.575664 a close relationship between home numeracy and preschoolers' mathematical development. There are several possible reasons for the discrepant findings, including the exact nature of numeracy activities provided, and possible unreliability of parental reports of home numeracy. However, parental attitudes might also lead to differing results: because attitudes might influence actual home numeracy provision or the ways in which it is reported; because parental attitudes and beliefs might be transmitted intergenerationally; and because parental mathematics anxiety may interact with home numeracy activities to create early negative emotional associations about mathematics, as some research suggests to be the case with regard to school-age children. There has been a significant amount of research in the first two of these areas, but very little in the third area with regard to preschoolers. It should be seen as an important area for further research.

Keywords: home numeracy, preschoolers, parental attitudes, parental beliefs, gender stereotypes, mathematics anxiety

\section{INTRODUCTION}

The aim of this article is to point out the importance of incorporating into definitions and models of the early home numeracy environment, not only home provision of numeracy activities for preschool children, but also parental attitudes to mathematics (LeFevre et al., 2009; Skwarchuk et al., 2014) and, in particular, parental emotional reactions to mathematics, in particular mathematics anxiety. The article will start by discussing definitional issues with regard to both 'home numeracy environment' and 'attitudes to mathematics'. In both cases, I will argue in favor of a broadly inclusive definition, whereby home numeracy environment includes not only activities but attitudes, and attitudes include not only cognitive evaluations but emotions. I will proceed to describe Skwarchuk et al.s home numeracy model; and then to review some evidence as to the predictive role of home numeracy environment on children's mathematical development; and to discuss reasons why this evidence does not lead to absolutely consistent conclusions on this issue. I will then discuss the possible differential role of different types of mathematical activities in predicting different aspects of 
mathematical development. I will then argue that it is insufficient to view home numeracy environment solely in terms of provision of mathematical activities, and that parental attitudes to mathematics are also important.

I will give some evidence from studies so far about how parental attitudes may affect children's mathematical development, both because of effects of parental attitudes on the quantity and quality of their provision of the mathematical activities, and because of intergenerational transmission of attitudes. I will point out that there has been relatively little research on the effects of parental emotions about mathematics such as mathematics anxiety on preschool children's mathematical development. A few studies of school-age children suggest that this may have a crucial impact. I will conclude by emphasizing the need for further study of this highly important topic.

Most studies suggest that numeracy-related activities at home have at least some influence on preschool children's numeracy development (LeFevre et al., 2002; Gunderson and Levine, 2011; Skwarchuk et al., 2014). This is often portrayed in terms of 'home numeracy environment', though it is not always clear how broadly this phrase should be interpreted, and whether it refers just to the activities provided for children, or also to the parents' own engagement in mathematical activities, their attitudes toward numeracy in general, and/or their expectations regarding their children's current and future numeracy performance. I would argue that the home numeracy environment needs to be seen as including not only the mathematical activities directly available to children, but all the characteristics of the home environment that involve mathematics, including parents' own mathematical activities and their attitudes and emotions regarding mathematics.

If we are to include parental attitudes and emotions toward mathematics in our definition of 'home numeracy environment', we need to define 'attitudes' in this context and specify what they do and do not include. It would generally be agreed that attitudes to mathematics include enjoyment of mathematics, self-rating of one's own mathematical ability, and expectations regarding one's ability to learn and improve mathematics skills in the future. In the context of home numeracy environment, attitudes should also be seen as including evaluations of one's children's mathematical ability and expectations of their future mathematical learning. Attitudes to mathematics are often defined and studied more broadly. For example, Fennema and Sherman (1976) include among their attitude measures not only confidence in one's mathematical ability, but also perceived usefulness of mathematics; perception of the support received from teachers; and gender stereotypes with regard to perceiving mathematics as a male domain. As discussed below, gender stereotypes are one of the topics that has received most study regarding how parental attitudes may influence children's mathematical performance.

A more potentially controversial issue is whether emotional reactions such as mathematics anxiety should be classed as attitudes. However, many theories of attitudes, such as Breckler's ABC model (Breckler, 1984), do include affective components, and I will here follow researchers such as $\mathrm{Ma}$ and Kishor (1997) in treating mathematics anxiety as an attitude. (This topic is discussed in more detail by Dowker et al. (2016)). It will be argued here that, while there is a general need for greater consideration of parental attitudes to mathematics as part of the home numeracy environment, there is a particular need for greater consideration of parental emotional reactions to mathematics, especially mathematics anxiety.

\section{HOME NUMERACY MODEL}

As a means of clarifying how specific aspects of home numeracy may predict specific aspects of children's mathematical development, Skwarchuk et al. (2014) proposed a Home Numeracy Model, based on a survey of parents of almost 200 children beginning kindergarten (median age 58 months). The parents were asked about their own attitudes toward numeracy (e.g., whether they enjoyed doing sums), their academic expectations for their children, and reports of formal and informal numeracy activities at home. The children were given numeracy tests a year later, involving both symbolic and nonsymbolic arithmetic. Hierarchical regression analyses were used to investigate what were predictors of numeracy test scores. Parents' reports of formal home numeracy practices (for example, practicing simple sums) predicted children's symbolic arithmetic, while their reports of children's exposure to games with numerical content predicted children's non-symbolic arithmetic. Parental attitudes toward arithmetic predicted mainly the children's non-symbolic arithmetic. Their model proposed that parental academic expectations for their children predict formal numeracy activities in the home, which in turn predict the children's formal (mainly symbolic) numeracy, while their own attitudes toward numeracy and the children's exposure to informal activities are predictors of the children's informal (mostly nonsymbolic) numeracy.

As discussed in the next section, many studies have indeed suggested that numeracy-related activities in the home do predict young children's mathematical performance. However, some studies have failed to support this hypothesis, and not all studies that do support it have shown the sharp distinction between informal and formal home numeracy practices that the model proposes.

\section{HOME NUMERACY ACTIVITIES: EVIDENCE FOR THEIR PREDICTIVE ROLE}

Most studies suggest that the extent of parental provision of home numeracy activities is correlated with children's current numeracy performance (Blevins-Knabe and Musun-Miller, 1996; Skwarchuk, 2009; De Florio and Beliakoff, 2015; Zippert and Ramani, 2017). This does not necessarily indicate that the home numeracy activities are causing the children's better numeracy performance. It could either reflect parental response to their children's interest and ability in numeracy, or parental influence on their children's numeracy ability: it is not possible to draw strong conclusions from a study of correlations at a single time-point.

Longitudinal studies do, however, give some support to the hypothesis that home numeracy environment influences 
children's future numeracy development (e.g., LeFevre et al., 2002; Gunderson and Levine, 2011; Skwarchuk et al., 2014). For example, Niklas and Schneider (2012, 2014) studied the home numeracy environment of about 600 German children starting kindergarten and followed them up longitudinally to the end of Grade 1. Family mathematical activities, such as playing dice or number games, predicted children's mathematical abilities, not only concurrently but longitudinally, even after controlling for IQ.

Dunst et al. (2017) carried out a meta-analysis of studies of relationships between early home numeracy activities and preschool children's mathematics performance. The metaanalysis included 13 studies of children between 36 and 84 months: a total of over 5,000 children in all. Results indicated that home numeracy experiences were associated with children's mathematical performance.

Most of the relevant studies have been carried out in Europe or North America; but some studies outside of these areas have given similar results. For example, Cheung et al. (2020) studied 290 preschool children living in low to middle income communities in the Philippines, and found that home numeracy resources and activities directly predicted children's numeracy skills, as did the parents' education, calculation fluency and own mathematical activities.

However, not all studies do show a strong relationship between home numeracy environment and young children's numeracy (Blevins-Knabe et al., 2000). Zippert et al. (2020) found a very limited level of association, but much less than in some of the other studies. They observed 45 parent-preschooler dyads engaging in three play activities: playing cards, building blocks, and stringing beads, all with activity suggestions from the researchers. The children underwent a mathematics and numeracy test (the Research-Based Early Mathematics Short Form), and additional tests of spatial skills and patterning, concurrently and 7 months later. Children's exploration of space and patterns correlated with their concurrent spatial and pattern skills, and parental support in numeracy correlated with children's concurrent numeracy abilities, but not with their growth in numeracy. Otherwise, parental mathematics support was not related to their children's concurrent or subsequent mathematical abilities. Missall et al. (2015) also found no statistically significant relationship between home numeracy activities and children's mathematical performance.

Wolf and McCoy (2019) in a study of 2,137 Ghanaian preschool children (mean age 5.2 years) found that, after taking SES into account, parental reports of cognitive stimulation at home (including, but not restricted, to numerical activities) was actually negatively related to children's motor, literacy and numeracy skills. This is most likely to be because parents were more likely to provide home stimulation to children who were showing signs of difficulties, rather than due to any actual negative effect of stimulation.

There are several possible reasons for the somewhat conflicting results. One of them is that the assessment of the level of home numeracy may not be totally reliable. One problem with the methodology of most studies of home numeracy is that they involve the parents answering questions or filling in questionnaires about their provision of home numeracy. Thus, the parental reports may be affected both by what the parents regard as socially desirable and by what they regard as mathematics. They may over-report provision of numeracy activities because they view provision of such activities as socially desirable, or may under-report them because they may only regard a limited range of activities as mathematical: the latter would seem most likely to include formal counting-type activities. Researchers can reduce the risk of such under-reporting by asking parents about specific activities, but this then carries the risk that the results will be influenced by the researchers' assumptions about what mathematical activities are likely to be provided.

A minority of studies involve researchers' observations of parental provision of numeracy activities, instead of, or in addition to, parental reports (Gunderson and Levine, 2011; Zippert et al., 2020). These observational studies avoid some of the problems of parental report studies, but have some problems of their own: if the researchers are non-directive, they may be relying a limited sample of observations, and if they are directive, they may influence the parents' practices in a way that does not reflect real life. Zippert et al. (2020) asked parents to engage in three types of activities with their children: card games, building with Lego Duplo blocks, and stringing beads. The researchers coded the frequency of various types of mathematical content within these activities (e.g., magnitude comparison, counting objects, numeral identification, mention of shapes, mention of spatial locations, verbal identification of patterns, nonverbal gesturing toward patterns). These activities were chosen to elicit mathematically related speech and behaviors by parents and children, but may not have resembled the parents' typical practices. Moreover, the constraints resulting from the researchers requesting specific types of activities may have to some degree reduced variability in the parents' behavior and this may have contributed to a reduction in the level of associations that were found. Even in observational studies where the researchers are not directive, the parents may behave uncharacteristically in response to being observed. It is noteworthy that some studies which included both parental reports and observational measures found little or no correlation between the two (Missall et al., 2015; Mutaf Yilsiz et al., 2018). It is important that studies in the future include both observational and parental report measures, and examine systematically which are better predictors of children's mathematical development.

\section{WHAT TYPES OF MATHEMATICAL ACTIVITIES PREDICT WHICH ASPECTS OF YOUNG CHILDREN'S MATHEMATICS?}

One factor that may influence findings about the importance of home numeracy is the particular aspects of mathematics that are studied. The very term 'home numeracy' seems to imply a focus on numbers and counting. Where home mathematics activities have been investigated from the point of view of comparing the extent of activities involving number skills and those involving other mathematical domains such as shape, space and pattern, it has generally been found that parents engage in a variety of mathematical activities, but emphasize number skills more than 
others (Zippert and Rittle-Johnson, 2020; Zippert et al., 2020). This is in fact not specific to the home. Similar results have been found for preschool teachers (Von Spreckelsen et al., 2019).

Several studies have examined the distinction made in the Home Numeracy Model (Skwarchuk et al., 2014) between formal and informal activities. Formal activities are typically defined as those that emphasize quasi-educational activities such as counting and numeral recognition, while informal activities include number games and numerical activities embedded in everyday tasks such as preparing meals. On the whole, studies support the Home Numeracy Model's hypothesis that more formal activities mainly predict symbolic skills, while more informal activities tend to predict non-symbolic skills (LeFevre et al., 2010; Ramani et al., 2015; Hart et al., 2016).

For example, Susperreguy et al. (2018) asked the parents of 390 Chilean preschoolers (mean age at start of study 4 years 7 months) about the home numeracy activities that they engaged in with their children, and about their attitudes toward numeracy and their early academic expectations for their children. They were also asked about home literacy activities. Parents with more positive attitudes toward numeracy and higher academic expectations for their children reported more formal numeracy activities (mapping and operational activities). Formal numeracy activities predicted children's number line estimation. Informal activities, such as parents' knowledge of number games, predicted non-symbolic arithmetic and non-symbolic number comparison tasks. Both types of activities predicted children's applied problem-solving skills. Home literacy activities were not related to children's early numeracy skills.

There have sometimes been variations in the findings of what is most predicted by different types of activity. (Mutaf Yildiz et al., 2018) found that formal home numeracy activities were associated with children's counting abilities, while informal home numeracy activities were associated with calculation and symbolic number line estimation. Benavides-Varela et al. (2016) studied 110 children (mean age 5 years 11 months) and found that their knowledge of number information learned at home, and their parents' reports of home numeracy activities predicted their exact but not their approximate number skills.

One type of informal home mathematical activity seems to be a particularly strong predictor of children's numeracy: playing numerical board games (Benavides-Varela et al., 2016; Ramani and Siegler, 2008; Ramani and Siegler, 2011). There is evidence that in this case, the board games play a causal role, as playing such games with children who have not played them at home seems to result in significant improvements in early numeracy knowledge (Ramani and Siegler, 2008; Ramani and Siegler, 2011).

Another aspect of home numeracy activities that may be influential is the complexity of the activities provided. (Thompson et al., 2017) studied 184 preschool children (71 three-year-olds and 113 four-year-olds and investigated their parents' reports of home numeracy activities and the children's numeracy skills. After controlling for parental educational level, the level of provision of home numeracy activities predicted the numeracy skills of the four-year-olds but not the three-year-olds. In the case of the four-year-olds, complex but not basic home numeracy activities predicted children's numeracy skills. Since complex activities were commoner for the older children, this might explain why home numeracy environment only predicted the numeracy skills of the older children. It is not clear whether the more complex home numeracy activities lead to better mathematical development, or whether parents are more likely to engage in complex numeracy activities with more mathematically advanced children.

It should be noted that parental reports of home numeracy activities do not usually give much indication of the quality of the parent-child interactions during these activities, and in particular of the quantity and quality of the mathematical language that the children hear during these activities. Knowledge of mathematical language has been shown to be an important aspect of mathematical development (e.g., Gunderson and Levine, 2011; Ramani et al., 2015; Thompson et al., 2017; Casey et al., 2018). The role of exposure to mathematical language in home numeracy activities warrants further study.

However important the types of activities provided are to children's mathematical development, they are unlikely to be the whole story. Parental attitudes toward mathematics are also likely to be important, as referenced in the Home Numeracy Model (Skwarchuk et al., 2014), and it is very important to study these.

\section{POSSIBLE EFFECTS OF PARENTAL ATTITUDES TOWARD MATHEMATICS ON CHILDREN'S MATHEMATICAL DEVELOPMENT}

It is well known that there is wide variation in attitudes toward mathematics, and that many people have extremely negative attitudes toward mathematics, often involving strong emotions of fear and anxiety (Hembree, 1990; Ashcraft, 2002; Carey et al., 2016; Dowker et al., 2016). Therefore, it must be assumed that the parents in studies of home numeracy will vary considerably in their attitudes toward mathematics, and it is likely that these variations in attitudes will affect children's experience of home numeracy, and the children's own attitudes and emotions toward mathematics.

Mathematics anxiety as such is not the main topic of this paper, which focusses specifically on its possible impact on the home numeracy environment of very young children. However, it is important to note that mathematics anxiety is common, though estimates of its exact frequency vary quite widely depending on the criteria used (Carey et al., 2016; Dowker et al., 2016); that it tends to increase with age during the school years (Gierl and Bisanz, 1995; Gottfried et al., 2007; Krinzinger et al., 2009; Ma and Kishor, 1997; Wigfield and Meece, 1988; but see; Sorvo et al., 2017); and that it is usually higher in females than males (Hembree, 1990; Else-Quest et al., 2010; Devine et al., 2012). It is negatively related to mathematics achievement and to pursuit of mathematical activities: for example, it is negatively associated with performance on secondary school and college mathematics examinations, and with choice to take advanced mathematics 
courses (Hembree, 1990; Ma and Kishor, 1997). The negative relationship between mathematics anxiety and mathematics performance is bidirectional ( $\mathrm{Ma}$ and $\mathrm{Xu}, 2004$; Carey et al., 2016; Ganley and Lubienski, 2016). Longitudinal studies show that attainment in mathematics negatively predicts mathematics anxiety (Maloney and Beilock, 2012; Jansen et al., 2013), presumably because experiences of failure are aversive and experiences of success are rewarding; but mathematics anxiety also predicts reduced attainment (Cargnelutti et al., 2017).

There are several ways, discussed in the following sections, in which negative parental attitudes toward mathematics, and in particular mathematics anxiety may affect their children's home numeracy experience. The first, perhaps most obvious way is that if parents have negative attitudes toward mathematics, they may be less likely to engage in mathematics-related activities at home at all, thus reducing their children's home numeracy exposure (Zippert et al., 2020). The second is that parents may pass their own negative attitudes on to their children (Szczygiel, 2020a; Szczygiel, 2020b). The third is that if parents have high levels of mathematics anxiety, their interactions with their children, when attempting to teach them aspects of mathematics or engage them in numeracy -related activities may be fraught and stressful (DiStefano et al., 2020). For example, parents may threaten their children with failure due to their own fear of failure, or be gloomy or bad-tempered with them because any mathematical activity causes them to be in a bad mood. This may lead to the children developing negative associations with mathematics.

\section{PARENTAL ATTITUDES AND PROVISION OF HOME NUMERACY ACTIVITIES}

Aspects of parental attitudes toward mathematics that have been studied in connection with links to home numeracy and to children's performance in mathematics are quite diverse and have included their beliefs about their own and their children's ability in mathematics (Blevins-Knabe et al., 2000; Hart et al., 2016; Zippert et al., 2020) their beliefs about the importance of mathematics to themselves and their children (Skwarchuk et al., 2014); their gender stereotypes about mathematics (Bleeker and Jacobs, 2004; Tomasetto et al., 2015; Del Rio et al., 2019); and -so far, almost exclusively with regard to school-age children - their level of anxiety about mathematics (Maloney et al., 2015; DiStefano et al., 2020; Vanbinst et al., 2020). As discussed below, gender stereotypes and parents' beliefs about their own and their children's numerical abilities seem to be the attitudes that have received the largest amount of study in this connection.

There is some evidence that parental beliefs about their children's and their own ability in mathematics may influence their provision of home mathematics activity, supporting the Home Numeracy Model's prediction that parental academic expectations for their children would influence their provision of formal numeracy activities in particular. For example, (Zippert et al., 2020), who examined a wider variety of home mathematical activities than typical, found that parents' beliefs about their children's abilities were positively related to their support for numeracy, pattern, and mathematics as a whole, while their beliefs about their own abilities were positively related to their support for spatial activities. With regard to their beliefs about their children's abilities, it is difficult to say whether their children's interest in mathematics is driving both the parents' beliefs and their numeracy provision, or whether a more general belief in children's mathematical capacity is leading to greater numeracy provision, or even whether their numeracy provision leads to greater interest and better performance on the part of their children, which in turn influences the parents' child-specific beliefs. With regard to the parents' beliefs about their own abilities, it is difficult to say whether their beliefs are directly affecting their mathematical provision for their children, or whether their actual ability in mathematics is influencing both their beliefs and their provision.

DeFlorio and Beliakoff (2015) studied 90 children in their first year of preschool and 88 in their prekindergarten year, and compared those from middle and lower SES backgrounds. There was relatively little difference in the extent of home mathematical activities that they received, but significant differences in parental beliefs about early mathematical development. Middle SES parents had higher expectations, and also a more accurate understanding of what skills can be expected from children by the age of 5 . The parents'beliefs were associated with their children's mathematical performance. Once again, it is hard to disentangle the effects of parental beliefs on their children's mathematical performance from the effects of children's performance on their parents' beliefs.

A number of studies indicate that parents' beliefs about their own interest and ability in mathematics are associated with their provision of home numeracy activities (BlevinsKnabe et al., 2000; Skwarchuk, 2009); but there are some that do not (Skwarchuk et al., 2014; Hart et al., 2016). Parents' beliefs about their children's abilities have been more consistently been found to be associated with home numeracy provision (Hart et al., 2016; Huntsinger et al., 2016). Parents who believed their children had high ability in numeracy tasks engaged in frequent home numeracy support. Parents' beliefs that attainment of early numeracy skills is important for their children have also been found to be associated with the home numeracy environment in some studies (Skwarchuk et al., 2014) but not in others (LeFevre et al., 2010).

It must be remembered that parental attitudes may influence not only actual provision of home numeracy, but parental reports of it, thus possibly biasing the results of surveys. As indicated above, parents' beliefs about what is mathematical may influence their reporting. For parents who are highly anxious about mathematics, certain activities may become particularly salient and more likely to be reported than others. One possible hypothesis is that such parents may place a particularly high emphasis on formal activities, because they are likely to associate such activities with the content of school instruction and in particular with school tests and examinations. This possibility must be considered when interpreting the results of studies of relationships between parental attitudes and home numeracy provision. 


\section{INTERGENERATIONAL TRANSMISSION OF NEGATIVE ATTITUDES: THE CASE OF GENDER STEREOTYPES}

Intergenerational transmission of negative attitudes toward mathematics also appears to occur. This has perhaps received more attention with regard to transmission of gender stereotypes about mathematics than other aspects of attitudes toward mathematics. As mentioned above, it is known that females tend to report more anxiety about mathematics than males, though nowadays males and females usually perform similarly in mathematics (Devine et al., 2012; Dowker et al., 2016). Among very young children, gender differences in mathematics anxiety are not so consistently found. Szczygiel (2020a) found that girls in early elementary grades showed greater mathematics test anxiety, but not greater anxiety about other aspects of mathematics, than boys. Evidence for transmission of mathematics anxiety by women to girls comes from studies of teachers as well as parents. Beilock et al. (2010) reported that mathematics anxiety in female elementary school teachers longitudinally predicted mathematics anxiety and reduced mathematical attainment in their female but not male pupils.

Some studies suggest intergenerational transmission of parental gender stereotypes even at a very young age, when children have had little or no school experience. Del Rio et al. (2019) studied a sample of Chilean five-year-olds and their parents. Both fathers and mothers showed gender stereotypes regarding mathematics ('mathematics is for boys') and fathers associated themselves with mathematics more than mothers did. These stereotypes seemed to have already been communicated to their children. Five-year-old boys already showed the stereotype, in implicit measures, that mathematics is for boys, though girls did not. Girls' mathematics self-concepts were positively related to their mothers' mathematics self-concepts, but negatively to their fathers' mathematical self-concepts. While it is possible that both parents and children were independently influenced by gender stereotypes about mathematics in the wider culture, it seems more likely, especially in view of the children's young age, that the parents' attitudes were being transmitted to their children.

Jacobs and colleagues (Jacobs, 1991; Bleeker and Jacobs, 2004) found that boys at all ages, tended to rate themselves higher in mathematics and to actually perform better if their fathers had strong gender stereotypes about mathematics, but such paternal stereotypes were associated with lower self-rating and lower actual performance by girls. If mothers had strong gender stereotypes about mathematics, both their sons and daughters tended to rate themselves lower and actually to perform worse in mathematics. The authors suggested, on the basis of path analyses that the parents' gender stereotypes influenced their perceptions of their children's abilities, which in turn influenced the children's own beliefs about their abilities and their actual performance. It cannot, however, be ruled out that the parents may have been aware of their children's level of mathematical performance, and that fathers, in particular, might have used gender stereotypes to explain these. The reason why mothers' gender stereotypes were associated with worse self-rating and performance by both sons and daughters may be that gender stereotyping by mothers was associated with a negative personal attitude to mathematics, which may have been transmitted to children of both genders and/or reduced their provision of home numeracy activities.

Tomasetto et al. (2015) studied a group of Italian 6-year-olds and their parents and also found associations between parents' gender stereotyping and children's self-rating, but it was not as consistent as in the previously mentioned studies. Girls' selfrating of their own mathematical performance was associated with their mothers', but not their fathers', gender stereotyping with regard to boys being better at mathematics. Boys' self-rating was not associated with gender stereotyping by either mother or father.

All the studies mentioned above lacked measures of parental mathematical performance, parental mathematics anxiety, or provision of home numeracy activities, which means that some of the interpretations must be speculative.

\section{POSSIBLE EFFECTS OF PARENTAL MATHEMATICS ANXIETY ON CHILDREN'S ANXIETY AND PERFORMANCE}

There is evidence that parental mathematics anxiety predicts mathematics anxiety and lower mathematical performance in their children, even when parental educational level is taken into account. For example, Vanbinst et al. (2020) found that sixth-grade children's mathematics anxiety was significantly associated with their mothers' mathematics anxiety and both their mothers' and fathers' educational level. Most relevant to the present review, parental mathematics anxiety appears to be negative predictor of young, though already school-age, children's performance in mathematics. Maloney et al. (2015) found that parental anxiety about mathematics is negatively correlated with their children's level of progress in mathematics in first and second grade. However, this is only the case if parents with high levels of mathematics anxiety also report providing frequent help with mathematics homework. In the case of parents, who did not often help with homework, there was no such relationship between parental mathematics anxiety and children's performance. Moreover, parental mathematics anxiety seemed to be specifically associated with children's performance in mathematics and was not related to their performance with regard to reading.

Szczygiel (2020b) found some associations between parental mathematics anxiety and young schoolchildren's mathematics anxiety and performance, but also found that these associations were highly dependent on the gender of the child, the gender of the parent, and the child's school grade. She found that mathematics anxiety in fathers was associated with mathematics anxiety in firstgrade children of both genders and in third grade girls, but not significantly with their children's mathematical achievement. Mathematics anxiety in mothers (and teachers) was associated with third grade children's mathematics anxiety, but not significantly with their achievement.

Since the parents' mathematical performance in these studies was not directly tested, it is not possible to rule out the possibility that the parents' mathematics anxiety was associated with their 
own limited understanding of mathematics, reducing their effectiveness in helping their children with mathematics. At first sight, it might appear unlikely that many parents would have difficulty with early primary school mathematics, but some studies suggest that severe numeracy difficulties in adults are surprisingly common (Parsons and Bynner, 2005). However, a more likely explanation is that if the parents are highly anxious about mathematics, they may transmit their anxiety to their children while assisting them with mathematics, or may react to their children's mistakes and failures with frustration or even with scolding or punishment.

Evidence for this proposed explanation comes from a study by (DiStefano et al., 2020), who found that level of mathematics anxiety in parents was associated with their reported level of conflict, stress, frustration, and emotionality when helping children with their mathematics homework. It is at least possible that these experiences of conflict and parents' expression of negative emotions build up negative associations with mathematics in children.

The above studies deal with children, who are already attending primary school, and receiving formal homework assignments. Could similar factors also affect preschool children's attitudes and performance in numeracy? This is something that still needs to be studied; but it is certainly not impossible. Parents, especially those who themselves have negative attitudes toward mathematics, may be more likely to express impatience or frustration with children who are demonstrating difficulties with counting or are slow at working out how to play a mathematics-related game. They may also demonstrate discomfort with mathematical activities and show more negative moods when carrying out such activities than at other times. This could at least in theory result in the children developing negative associations with mathematics from a very early age. It is important to investigate whether this is indeed the case, and, if so, whether it applies more to formal or informal numerical activities. The Home Numeracy Model might suggest that informal numerical activities might be more affected, as it indicates that parental attitudes toward numeracy mainly predict provision of informal activities. However, it must be remembered that 1) the Home Numeracy Model deals with the extent and type of provision of such activities, not with the emotions associated with them; and 2) the research on which the model was based (Skwarchuk et al., 2014) included relatively few parents with extremely negative attitudes toward mathematics. It is quite possible that parental negative emotions toward mathematics would be stronger and more likely to be transmitted to children in the case of formal home numeracy activities than that of informal home numeracy activities, as parents may be more likely to associate the former with their negative experiences and anxieties relating to school mathematics.

\section{AREAS FOR FUTURE RESEARCH}

The focus of studies of home numeracy and its effects on very young children has usually not focused strongly on parental attitudes to mathematics, and, in particular, has not generally emphasized parental emotional reactions to mathematics. Where attitudes have been studied, this has usually involved the more cognitive aspects of attitudes such as beliefs and stereotypes, rather than emotions such as anxiety. Yet there is much evidence both that adult emotional reactions to mathematics are highly variable and often negative (Hembree, 1990; Ashcraft, 2002; Maloney and Beilock, 2012; Dowker et al., 2016), and that these emotions may influence both the provision of mathematical activities for their school-age children, and the ways in which school-age children respond to these activities (Maloney et al., 2015; DiStefano et al., 2020).

Although the Home Numeracy Model (Skwarchuk et al., 2014) incorporates parental attitudes toward mathematics, and although the attitude measures that it references include questions about anxiety, the effects of parental mathematics anxiety on preschoolers have so far received remarkably little study. If we are to gain a fuller understanding both of the role of early home numeracy activities, and of the origins of mathematics anxiety in children, it is vital to carry out more studies of the effects on preschoolers of such parental emotions. The factors need to be studied both with regard to their influences on the provision of home numeracy activities, and with regard to children's responses to home numeracy, including the possible intergenerational transmission of mathematics anxiety.

It is also important to go beyond numeracy in the narrower sense and carry out more studies of the influences of parental attitudes and emotions on the provision and effects of other aspects of mathematics, such as shape, space, measurement, and pattern. These aspects of mathematics are important in children's mathematical development, and are known to feature in home numeracy activities (Zippert et al., 2020); but even less is known about the possible influence of parental attitudes and emotions on these than on numeracy in the narrower sense. It is important to expand our knowledge in this area.

It is also important to investigate systematically whether different aspects of parental mathematics anxiety may have different effects on home numeracy provision, and on its possible predictive role in children's mathematical performance. For example, some studies (Wigfield and Meece, 1988; Sorvo et al., 2017) indicate separate components of mathematics anxiety: cognitive (performance anxiety) and affective (negative emotional reactions to numerical stimuli). It is at least possible that the cognitive component might result in more pressure for success and negative reactions to failure in association with home numeracy activities, while the affective component might be more likely to result in avoidance of provision of home numeracy activities.

Finally, if we are to understand the interactions between the effects of home numeracy environment and parental mathematics anxiety, an important issue is the question of how early children can develop mathematics anxiety and other negative attitudes toward mathematics. In general, younger children tend to show more positive attitudes and less anxiety than older children (e.g., Ma and Kishor, 1997; Krinzinger et al., 2009). However, several studies indicate that even school beginners can demonstrate mathematics anxiety (Ramirez 
et al., 2013; Vukovic et al., 2013; Jameson, 2014; Petronzi, 2016). It has not been established whether preschoolers can show the beginnings of anxiety or other negative reactions to numbers and counting, and whether parents' negative attitudes toward mathematics can influence preschool children's reactions; and this is an important topic for future study. Studying mathematics anxiety and attitudes in preschoolers may be more difficult than studying the same things in older, more articulate children. However, methods have already been devised for assessing mathematics anxiety in children as young as four in the United Kingdom, where formal schooling typically begins at around this age (Petronzi, 2016; Petronzi et al., 2017; Petronzi et al., 2019). By extending these methods to children in countries where formal schooling begins at a later age, it may be possible to investigate whether mathematics anxiety may sometimes have roots in experiences even before schooling begins.

Learning more about the possible role of parental mathematics anxiety in children's mathematical development may have important practical and educational implications. If parental

\section{REFERENCES}

Ashcraft, M. H. (2002). Math anxiety: personal, educational, and cognitive consequences. Curr. Dir. Psychol. Sci. 11, 181-185. doi:10.1111/1467-8721.00196

Beilock, S. L., Gunderson, E. A., Ramirez, G., and Levine, S. C. (2010). Female teachers' math anxiety affects girls' math achievement. Proc. Natl. Acad. Sci. Unit. States Am. 107, 1860-1863. doi:10.1073/pnas.0910967107

Benavides-Varela, S., Butterworth, B., Burgio, F., Arcara, G., Lucangeli, D., and Semenza, C. (2016). Numerical activities and information learned at home link to exact numeracy skills in 5-6 years-old children. Front. Psychol. 7, 94. doi:10. 3389/fpsyg.2016.00094

Bleeker, M. M., and Jacobs, J. E. (2004). Achievement in math and science: do mothers' beliefs matter 12 years later? J. Educ. Psychol. 96 (1), 97-109. doi:10. 1037/0022-0663.96.1.97

Blevins-Knabe, B., Austin, A. B., Musun, L., Eddy, A., and Jones, R. M. (2000). Family home care providers' and parents' beliefs and practices concerning mathematics with young children. Early Child. Dev. Care. 165, 41-58. doi:10. 1080/0300443001650104

Blevins-Knabe, B., and Musun-Miller, L. (1996). Number use at home by children and their parents and its relationship to early mathematical performance. Early Dev. Parent. 5 (1), 35-45. doi:10.1002/(SICI)1099-0917(199603)5:1<35::AIDEDP113>3.0.CO;2-0

Breckler, S. J. (1984). Empirical validation of affect, behavior, and cognition as distinct components of attitude. J. Pers. Soc. Psychol. 47 (6), 1191-1205. doi:10. 1037/0022-3514.47.6.1191

Carey, E., Hill, F., Devine, A., and Szücs, D. (2016). The chicken or the egg? The direction of the relationship between mathematics anxiety and mathematics performance. Front. Psychol. 6, 1987. doi:10.3389/fpsyg.2015.01987

Cargnelutti, E., Tomasetto, C., and Passolunghi, M. C. (2017). The interplay between affective and cognitive factors in shaping early proficiency in mathematics. Trends Neurosci. Educ. 8-9, 28-36. doi:10.1016/j.tine.2017.10.002

Casey, B., Lombardi, C. M., Thomson, D., Nguyen, H. N., Paz, M., Theriault, C., et al. (2018). Maternal support of early numerical concept learning predicts preschool and first grade math achievement. Child Dev. 89 (1), 156-173. doi:10. 1016/j.ecresq.2017.07.004

Cheung, S. K., Dulay, K. M., and McBride, C. (2020). Parents' characteristics, home environment, and children's numeracy skills: how are they related in low- to middle-income families in the Philippines? J. Exp. Child Psychol. 192, 104780. doi:10.1016/j.jecp.2019.104780

DeFlorio, L., and Beliakoff, A. (2015). Numeracy activities and parent beliefs. Early Educ. Dev. 26, 319-341. doi:10.1080/10409289.2015.968239 anxiety has a highly negative effect on children's attitudes and/ or performance, then it would be desirable to find ways of treating and reducing parents' anxiety, for their children's sake as well as their own. If it is important only if the parents engage in a lot of home numeracy activities with their children, then perhaps home numeracy activities should not be encouraged if the parents are highly anxious, and perhaps might be replaced by preschool numeracy programmes. If, on the other hand, parental mathematics anxiety seems not to affect children directly, but reduces provision of home numeracy activities, perhaps parents with high mathematics anxiety should be actively encouraged to provide such activities. Much more research is needed in order to guide such decision-making.

\section{AUTHOR CONTRIBUTIONS}

The author confirms being the sole contributor of this work and has approved it for publication.

Del Rio, M. F., Strasser, K., Cvencek, D., Susperreguy, M. I., and Meltzoff, A. N. (2019). Chilean kindergarten children's beliefs about mathematics: family matters. Develop. Psychol. 55, 687-702. doi:10.1037/dev0000658

Devine, A., Fawcett, K., Szucs, D., and Dowker, A. (2012). Gender differences in mathematics anxiety and the relation to mathematics performance while controlling for test anxiety. Behav. Brain Funct. 8, 33. doi:10.1186/1744-9081-8-33

DiStefano, M., O’Brien, B., Storozuk, A., Ramirez, G., and Maloney, E. (2020). Exploring math anxious parents' emotional experience surrounding math homework-help. Int. J. Educ. Res. 99, 101526. doi:10.1016/j.ijer.2019.101526

Dowker, A., Sarkar, A., and Looi, C. Y. (2016). Mathematics anxiety: what have we learned in 60 years? Front. Psychol. 7, 508. doi:10.3389/fpsyg.2016.00508

Dunst, C. J., Hamby, D. W., Wilkie, H., and Dunst, K. S. (2017). "Meta-analysis of the relationship between home and family experiences and young children's early numeracy learning," in Engaging families as children's first mathematics educators: international perspectives. 2nd Edn, Editors S. Phillipson, A. Gervasoni, and P. Sullivan (Heidelberg, Germany: Springer), 105-125. doi:10.1007/978-981-10-2553-2_7

Else-Quest, N., Hyde, J. S., and Linn, M. (2010). Cross-national patterns of gender differences in mathematics: a meta-analysis. Psychol. Bull. 136, 103-127. doi:10. 1037/a0018053

Fennema, E., and Sherman, J. A. (1976). Fennema-Sherman mathematics attitudes scales: instruments designed to measure attitudes toward the learning of mathematics by females and males. J. Res. Math. Educ. 7, 324-326. doi:10. $2307 / 748467$

Ganley, C. M., and Lubienski, S. T. (2016). Mathematics confidence, interest, and performance: examining gender patterns and reciprocal relations. Learn. Indiv Differ. 47, 182-193. doi:10.1016/j.lindif.2016.01.002

Gierl, M. J., and Bisanz, J. (1995). Anxieties and attitudes related to mathematics in grades 3 and 6. J. Exp. Educ. 63, 139-158. doi:10.1080/00220973.1995.9943818

Gottfried, A. E., Marcoulides, G. A., Gottfried, A. W., Oliver, P. H., and Guerin, G. W. (2007). Multivariate latent change modelling of developmental decline in academic intrinsic math motivation and achievement: childhood through adolescence. Int. J. Behav. Dev. 31, 317-327. doi:10.1177/0165025407077752

Gunderson, E. A., and Levine, S. C. (2011). Some types of parent number talk count more than others: relations between parents' input and children's cardinal number knowledge. Dev. Sci. 14, 1021-1032. doi:10.1111/j.1467-7687.2011. 01050.x

Hart, S. A., Ganley, C. M., and Purpura, D. J. (2016). Understanding the home math environment and its role in predicting parent report of children's math skills. PloS One. 11, e0168227. doi:10.1371/journal.pone.016822

Hembree, R. (1990). The nature, effects, and relief of mathematics anxiety. J. Res. Math. Educ. 21, 33-46. doi:10.2307/749455 
Huntsinger, C., Jose, P., and Luo, Z. (2016). Parental facilitation of early mathematics and reading skills and knowledge through encouragement of home-based activities. Early Child. Res. Q. 37, 1-15. doi:10.1016/j.ecresq.2016.02.005

Jacobs, J. E. (1991). Influences of gender stereotypes on parent and child mathematics attitudes. J. Educ. Psychol. 83, 518-527. doi:10.1037/0022-0663.83.4.518

Jameson, M. M. (2014). Contextual factors related to math anxiety in second-grade children. J. Exp. Educ. 82, 518-536. doi:10.1080/00220973.2013.813367

Jansen, B. R. J., Louwerse, J., Straatemeier, M., Van der Ven, S. H. G., Klinkenberg, S., and Van der Maas, H. L. J. (2013). The influence of experiencing success in math on math anxiety, perceived math competence, and math performance. Learn. Indiv. Differ. 24, 190-197. doi:10.1016/j.lindif.2012.12.014

Krinzinger, H., Kaufmann, L., and Willmes, L. (2009). Math anxiety and math ability in early primary school years. J. Psychoeduc. Assess. 27, 206-225. doi:10. 1177/0734282908330583

LeFevre, J.-A., Polyzoi, E., Skwarchuk, S. L., Fast, L., and Sowinski, C. (2010). Do home numeracy and literacy practices of Greek and Canadian parents predict the numeracy skills of kindergarten children? Int. J. Early Years Educ. 18, 55-70. doi:10.1080/09669761003693926

LeFevre, J. A., Clarke, T., and Stringer, A. P. (2002). Influences of language and parental involvement on the development of counting skills: comparisons of French- and English-speaking Canadian children. Early Child. Dev. Care. 172, 283-300. doi:10.1080/03004430212127

LeFevre, J. A., Skwarchuk, S. L., Smith-Chant, B. L., Fast, L., Kamawar, D., and Bisanz, J. (2009). Home numeracy experiences and children's math performance in the early school years. Can. J. Behav. Sci. 41, 55-66. doi:10.1037/a0014532

Ma, X., and Kishor, N. (1997). Assessing the relationship between attitude toward mathematics and achievement in mathematics: a meta-analysis. J. Res. Math. Educ. 28, 26-47. doi:10.2307/749662

$\mathrm{Ma}, \mathrm{X}$., and Xu, J. (2004). Determining the causal order between attitude toward mathematics and achievement in mathematics. Am. J. Educ. 100, 256-281. doi:10.1086/383074

Maloney, E. A., and Beilock, S. (2012). Math anxiety: who has it, why it develops, and how to guard against it. Trends Cognit. Sci. 16, 404-406. doi:10.1016/j.tics. 2012.06.008

Maloney, E. A., Ramirez, G., Gunderson, E. A., Levine, S. C., and Beilock, S. L. (2015). Intergenerational effects of parents' math anxiety on children's math achievement and anxiety. Psychol. Sci. 26, 1480-1488. doi:10.1177/0956797615592630

Missall, K., Hoinoski, R., Caskie, G., and Repasky, P. (2015). Home numeracy environments of preschoolers: examining relations among mathematical activities, parent mathematical beliefs and early mathematical skills. Early Educ. Dev. 26, 356-376. doi:10.1080/10409289.2015.968243

Mutaf Yilsiz, B., Sasanguie, D., DeSmedt, B., and Reynvoet, B. (2018). Frequency of home numeracy activities is differentially related to basic number processing and calculation skills in kindergartners. Front. Psychol. 9, 340. doi:10.3389/ fpsyg.2018.00340

Niklas, F., and Schneider, W. (2014). Casting the die before the die is cast: the importance of the home numeracy environment for preschool children. Eur. J. Psychol. Educ. 29, 327-345. doi:10.1007/s10212-013-0201-6

Niklas, F., and Schneider, W. (2012). The impact of Home Numeracy Environment on the development of mathematical competencies from pre-school until the end of Grade 1. J. Family Res. 24, 134-147.

Parsons, S., and Bynner, J. (2005). Does numeracy matter more? London, United Kingdom: NRDC.

Petronzi, D., Staples, P., Sheffield, D., Hunt, T., and Fitton-Wilde, S. (2019). Further development of the children's mathematics anxiety scale UK (CMAS-UK) for ages 4-7 years. Educ. Stud. Math. 100, 231-249. doi:10.1007/s10649-018-9860-1

Petronzi, D., Staples, P., Sheffield, D., Hunt, T., and Fitton-Wilde, S. (2017). Numeracy apprehension in young children: insights from children aged 47 years and primary care providers. Psychol. Educ. 54, 1-33.

Petronzi, D. (2016). The development of the numeracy apprehension scale for children aged 4-7 years: qualitative exploration of associated factors and quantitative testing. Ph.D. Thesis. University of Derby.

Ramani, G. B., Rowe, M. L., Eason, S. H., and Leech, K. A. (2015). Math talk during informal learning activities in Head Start families. Cognit. Dev. 35, 15-33. doi:10.1016/j.cogdev.2014.11.002

Ramani, G. B., and Siegler, R. S. (2008). Promoting broad and stable improvements in low-income children's numerical knowledge through playing number board games. Child Dev. 79, 375-394. doi:10.1111/j.1467-8624.2007.01131.x
Ramani, G. B., and Siegler, R. S. (2011). Reducing the gap in numerical knowledge between low- and middle-income pre-schoolers. J. Appl. Dev. Psychol. 32, 146-169. doi:10.1016/j.appdev.2011.02.005

Ramirez, G., Gunderson, E. A., Levine, S. C., and Beilock, S. L. (2013). Math anxiety, working memory and math achievement in early elementary school. J. Cognit. Dev. 14, 187-202. doi:10.1080/15248372.2012.664593

Skwarchuk, S. L. (2009). How do parents support preschoolers' numeracy learning experiences at home?. Early Child. Educ. J. 37, 189-197. doi:10.1007/s10643009-0340-1

Skwarchuk, S. L., Sowinski, C., and LeFevre, J. A. (2014). Formal and informal home learning activities in relation to children's early numeracy and literacy skills: the development of a home numeracy model. J. Exp. Child Psychol. 121, 63-84. doi:10.1016/j.jecp.2013.11.006

Sorvo, R., Koponen, T., Viholainen, H., Aro, T., Raikkönen, E., Peura, P., et al. (2017). Math anxiety and its relationship with basic arithmetic skills among primary school children. Br. J. Educ. Psychol. 87, 309-327. doi:10.1111/bjep.12151

Susperreguy, M. I., Douglas, H., Xu, C., Molina-Rojas, N., and LeFevre, J.-A. (2018). Expanding the home numeracy model to Chilean children: relations among parental expectations, attitudes, activities, and children's mathematical outcomes. Early Child. Res. Q. 50, 16-28. doi:10.1016/j.ecresq.2018.06.010

Szczygiel, M. (2020a). Gender, general anxiety, math anxiety and math achievement in early school-age children. Issues Educ. Res. 30, 1126-1142.

Szczygiel, M. (2020b). When does math anxiety in parents and teachers predict math anxiety and math achievement in elementary school children? The role of gender and grade year. Soc. Psychol. Educ. 23, 1023-1054. doi:10.1007/s11218-020-09570-2

Thompson, R. J., Napoli, A. R., and Purpura, D. J. (2017). Age-related differences in the relation between the home numeracy environment and numeracy skills. Infant Child Dev. 26, e2019. doi:10.1002/icd.2019

Tomasetto, C., Mirisola, A., Galdi, S., and Cadinu, M. (2015). Parents' math-gender stereotypes, children's self-perception of ability, and children's appraisal of parents' evaluations in 6-year-olds. Contemp. Educ. Psychol. 42, 186-198. doi:10.1016/j.cedpsych.2015.06.007

Vanbinst, K., Bellon, E., and Dowker, A. (2020). Mathematics anxiety: an intergenerational approach. Front. Psychol. 11, 1648. doi:10.3389/fpsyg.2020. 01648

Von Spreckelsen, M., Dove, E., Coolen, I., Mills, A., Dowker, A., Sylva, K., et al. (2019). Let's talk about maths: the role of observed "maths-talk" and maths provisions in preschoolers' numeracy. Mind Brain Educ. 13, 326-340. doi:10. $1111 /$ mbe. 12221

Vukovic, R. K., Kieffer, M. J., Bailey, S. P., and Harari, R. R. (2013). Mathematics anxiety in young children: concurrent and longitudinal associations with mathematical performance. Contemp. Educ. Psychol. 38, 1-10. doi:10.1016/j. cedpsych.2012.09.001

Wigfield, A., and Meece, J. L. (1988). Math anxiety in elementary and secondary school students. J. Educ. Psychol. 80, 210-216. doi:10.1037/0022-0663.80.2.210

Wolf, S., and McCoy, D. C. (2019). Household socioeconomic status and parental investments: direct and indirect relations with school readiness in Ghana. Child Dev. 90, 260-278. doi:10.1111/cdev.12899

Zippert, E. L., Douglas, A. A., Smith, M. R., and Rittle-Johnson, B. (2020). Preschoolers' broad mathematics experiences with parents during play. J. Exp. Child Psychol. 192, e104757. doi:10.1016/j.jecp.2019.10475

Zippert, E. L., and Ramani, G. B. (2017). Parents' estimations of preschoolers' number skills relate to at-home number-related activity engagement. Infant Child Dev. 26 (2), 24. doi:10.1002/icd.1968

Zippert, E. L., and Rittle-Johnson, B. (2020). The home math environment: more than numeracy. Early Childhood Res. Quart. 50, 4-15. doi:10.1016/j.ecresq. 2018.07.009

Conflict of Interest: The author declares that the research was conducted in the absence of any commercial or financial relationships that could be construed as a potential conflict of interest.

Copyright $\odot 2021$ Dowker. This is an open-access article distributed under the terms of the Creative Commons Attribution License (CC BY). The use, distribution or reproduction in other forums is permitted, provided the original author(s) and the copyright owner(s) are credited and that the original publication in this journal is cited, in accordance with accepted academic practice. No use, distribution or reproduction is permitted which does not comply with these terms. 